\title{
Acanthopanax koreanum Roots Inhibit the Expression of Pro-Inflammatory Cytokines, Inducible Nitric Oxide Synthase, and CyclooxyGenase-2 in RAW 264.7 Macrophages
}

\author{
EUN-JIN YANG ${ }^{1}$, KWANG HEE HYUN ${ }^{2}$, HYUN KIM³, \\ MIN-JIN KIM ${ }^{1}$, NAM HO LEE ${ }^{1}$ and CHANG-GU HYUN ${ }^{1 *}$ \\ ${ }^{1}$ Cosmetic Sciences Center, Departmentof Chemistry and Cosmetics, \\ Jeju National University, Jeju 690-756, Korea. \\ ${ }^{2}$ Helios Co., Ltd., Sanchundan Dong-gil 16, Jeju 690-121, Korea. \\ ${ }^{*}$ Corresponding author E-mail: cghyun @jejunu.ac.kr \\ http://dx.doi.org/10.13005/ojc/320103
}

(Received: December 17, 2015; Accepted: March 25, 2016)

\begin{abstract}
Acanthopanax koreanum is a popular plant found onJejulsland, Korea and is commonly used to prevent the side effects of consumption of alcoholic beverages. However, this plant has not been properly utilized as a medicinal material. In this study, we investigated the anti-inflammatory effects of the $70 \%$ ethanol extract of $A$. koreanum roots (AKR-E). The results indicated that the AKR-E $(200 \mu \mathrm{g} / \mathrm{mL})$ inhibited the lipopolysaccharide (LPS)-induced production of nitric oxide (NO) and prostaglandin $\mathrm{E}_{2}\left(\mathrm{PGE}_{2}\right)$ in RAW 264.7 macrophages by $41.2 \%$ and $78.9 \%$, respectively. These effects were accompanied by concentration-dependent decreases in the expression levels of inducible NO synthase (iNOS) and cyclooxygenase-2 (COX-2) proteins. Additionally, the AKR-E inhibitedthe expression of pro-inflammatory cytokines, including interleukin (IL)-6 (22.7\%) and IL-1 $\beta$ (74\%). These data showed that the AKR-E had protective effects against the induction of LPS-induced inflammation in RAW 264.7 macrophages.
\end{abstract}

Key words: Acanthopanaxkoreanum roots, cyclooxygenase-2, inducible nitric oxide synthase, interleukin-6, interleukin-1 $\beta$.

\section{INTRODUCTION}

Acanthopanax species are widely distributed throughout Korea, China, and Japan. In particular, Acanthopanaxkoreanum Nakai(Araliaceae), an indigenous plant of Jejulsland in South Korea, has been used for the treatment of rheumatism, diabetes, and hepatitis ${ }^{1-3}$. Recent studies have suggested that $A$. koreanumhas protective effects against severe hepatitis induced by lipopolysaccharide (LPS) 
and $\mathrm{D}$-galactosamine (D-GalN) in mouse and rat models ${ }^{4,5}$.

Inflammation, which is characterized by heat, swelling, fever, and pain, is an important defensive mechanism that functions to alleviate injury and protect against infection $n^{6,7}$. Macrophages, a main component of the inflammatory pathway, are involved in the early response to LPS, a component of the outer membrane of gram-negative bacteria and a ligand of Toll-like receptor 4 (TLR4)that activates a variety of immunological responses. Macrophages infected early response to LPS, and also play a pivotal role in host defense and homeostasis. However, continuous stimulation of macrophages by LPS results in cell death and excessive secretion of inflammatory mediators, such as nitric oxide (NO), prostaglandin $\mathrm{E}_{2}\left(\mathrm{PGE}_{2}\right)$, interleukin (IL)-6, and IL-1 $\beta^{8-}$

${ }^{12}$.Moreover, in previous studies, we demonstrated the anti-inflammatory effects of $A$. koreanum fruit waste on LPS-induced RAW 264.7 macrophages and showed that this mechanism was dependent on inhibitor of kappa B alpha $\left(I_{\kappa} B-\alpha\right)^{1}$. However, the anti-inflammatory effects of $A$. koreanum roots have not yet been proven.

In this study, we examined whether treatment with $A$. koreanum roots could inhibit the
LPS-induced expression of inflammatory mediators and pro-inflammatory cytokines, such as $\mathrm{NO}, \mathrm{PGE}_{2}$, IL-6, and IL-1 $\beta$ in RAW 264.7 macrophages.

\section{MATERIALS AND METHODS}

\section{Reagents}

Dulbecco's modified Eagle's medium (DMEM) and fetal bovine serum (FBS) were purchased from Gibco (Grand Island, NY, USA). LPS (Escherichia coli 0111:B4) was purchased from Sigma Aldrich (St. Louis, MO, USA). All other chemicals used were of analytical grade. IL-6 (BD Bioscience, Mountain View, CA, USA), PGE ${ }_{2}$, and IL-1 $\beta$ (R\&D Systems, St. Louis, MO, USA) in the supernatants of cultured RAW 264.7 macrophages were measured using enzyme-linked immunosorbent assay (ELISA) kits according to the manufacturer's instructions. Antibodies against iNOSwere purchased from Calbiochem (San Diego, CA, USA), and antibodies against COX-2 were purchased from $B D$ Biosciences (San Diego, CA, USA).

\section{Cell Culture}

Murine RAW 264.7 macrophages were purchased from the Korean Cell Line Bank (Seoul, Korea). Cells were cultured in DMEM containing 2 $\mathrm{mM}$ glutamine, $10 \mathrm{mM}$ HEPES, penicillin $(100 \mathrm{U} / \mathrm{mL})$,

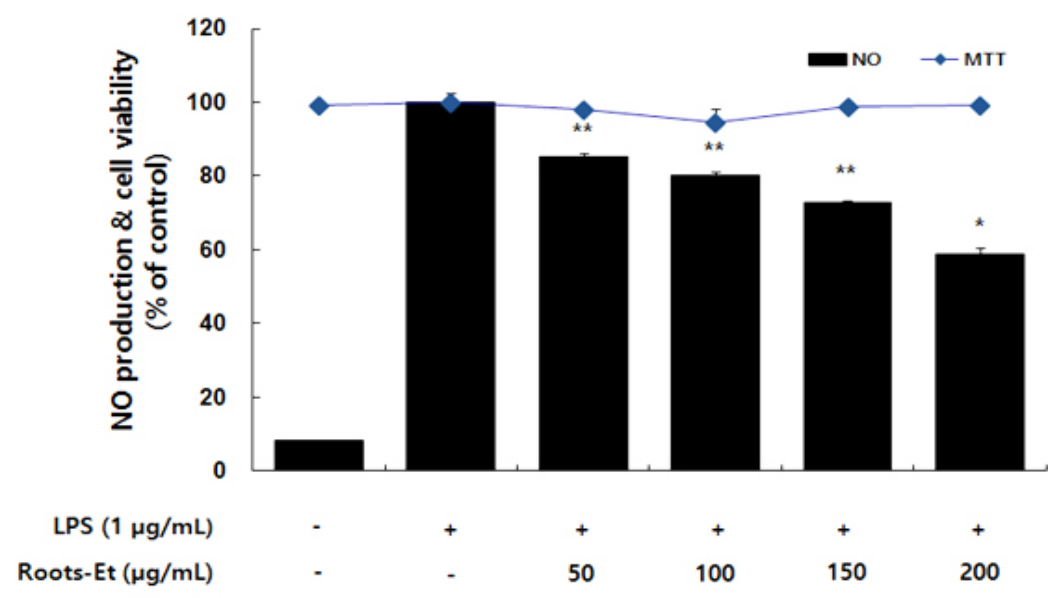

Fig. 1: Effects of the AKR-E on nitric oxide production in LPS-stimulated RAW264.7 macrophages. The cells were stimulated with $1 \mu \mathrm{g} / \mathrm{mL}$ LPS only or with LPS plus various concentrations (50, 100,150 , or $200 \mu \mathrm{g} / \mathrm{mL}$ ) of the AKR-E for $24 \mathrm{~h}$. Nitric oxide production was determined by the Griess reagent method. Cell viability was determined from the $\mathbf{2 4} \mathrm{h}$ culture of cells stimulated with LPS $(1 \mu \mathrm{g} / \mathrm{mL})$ in the presence of the AKR-E. The data represent the means \pm SDs of triplicate experiments. ${ }^{*} \mathrm{P}<0.05,{ }^{\star *} \mathrm{P}<0.01$ versusLPS alone. 
streptomycin $(100 \mu \mathrm{g} / \mathrm{mL})$, and 10\% FBS. Cells were cultured at $37^{\circ} \mathrm{Cin}$ a humidified incubator containing $5 \% \mathrm{CO}_{2}$.

\section{3-(4,5-Dimethylthiazol-2yl)-,5-Diphenyltetra-} zolium Bromide (MTT) Assays for cell Viability

Cell viability was determined using MTT assays $^{13,14}$. RAW 264.7 cells were cultured in 24-well plates for $18 \mathrm{~h}$, followed by treatment with various concentrations $(50,100,150$, or $200 \mathrm{ig} / \mathrm{mL})$ of the EtOHextract of A.koreanumroots (AKR-E) for $24 \mathrm{~h}$. Briefly, MTT was added to cells and the formazan crystals were dissolved in dimethyl sulfoxide (DMSO). The absorbance was measured at $540 \mathrm{~nm}$. The percentage of cells showing cytotoxicity was determined relative to that in the control group.

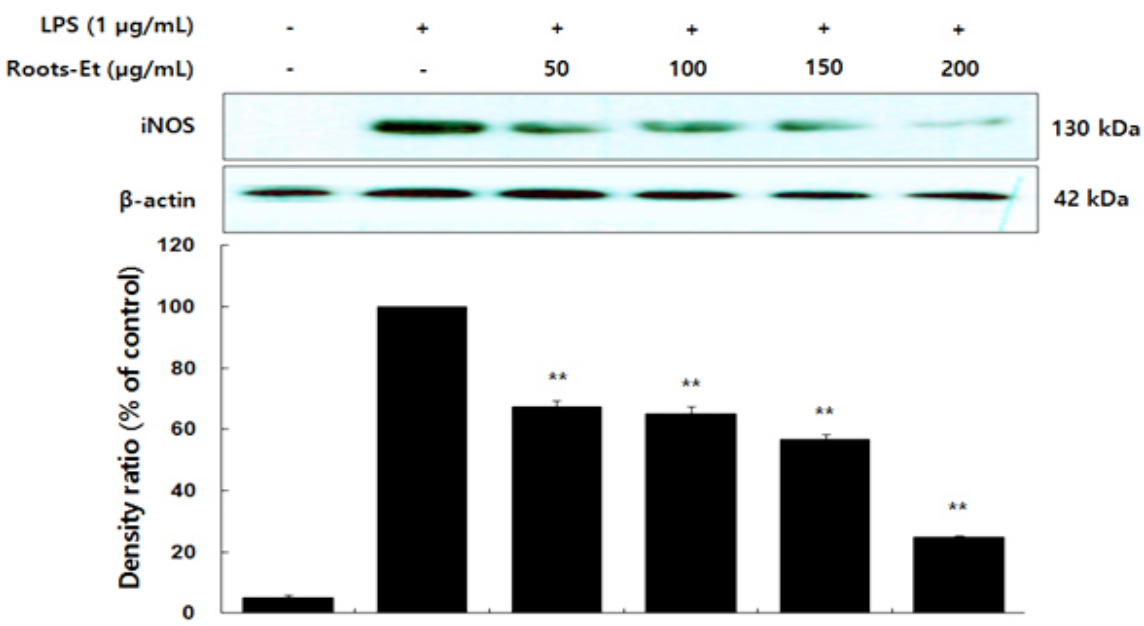

Fig. 2: Effects of the AKR-E on the activation of iNOS in LPS-stimulated RAW 264.7 macrophages. RAW 264.7 macrophages $(5.0 \times 105 \mathrm{cells} / \mathrm{mL})$ were stimulated with LPS $(1 \mu \mathrm{g} / \mathrm{mL})$ in the AKR-E (50, 100,150 , or $200 \mu \mathrm{g} / \mathrm{mL}$ ) for $24 \mathrm{~h}$. Whole-cell lysates $(25 \mu \mathrm{g})$ were prepared, and the proteins were separated by SDS-PAGE. The expression of iNOS and $\beta$-actin was determined by western blotting.

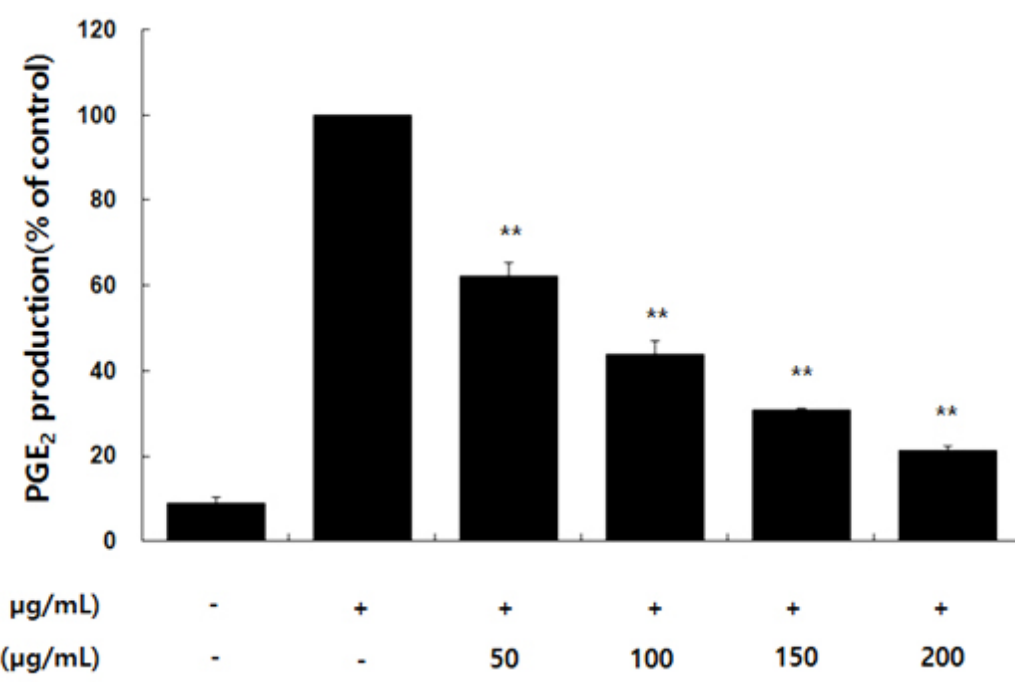

Fig. 3: Effects of the AKR-E on PGE2 production in LPS-stimulated RAW 264.7 macrophages. The cells were stimulated with $1 \mu \mathrm{g} / \mathrm{mL}$ LPS only or with LPS plus various concentrations (50, 100,150 , or $200 \mu \mathrm{g} / \mathrm{mL}$ ) of the AKR-E for $24 \mathrm{~h}$. PGE2production was assayed by ELISA. The data represent the means \pm SDs of triplicate experiments. ${ }^{*} P<0.05$, ${ }^{\star \star} P<0.01$ versus $L P S$ alone. 


\section{NO Assays}

$\mathrm{NO}$ accumulation was used as an indicator of NO production in the cell culture medium using Griess reagent ${ }^{15,16}$. The culture supernatant $(100 \mu \mathrm{L})$ was mixed with the same volume of Griess reagent ( $1 \%$ sulfanilamide and $0.1 \% N$-(1-naphthyl)ethylenediaminedihydrochloride in $5 \%$ phosphoric acid) for $10 \mathrm{~min}$, and absorbance was measured at $540 \mathrm{~nm}$.

\section{Western blot analysis}

After incubation for $24 \mathrm{~h}$, the cells washed twice with cold phosphate-buffered saline (PBS), lysed in lysis buffer (RIPA buffer, 1\% Nonidet P-40, $1 \%$ protease inhibitor cocktail), and kept on ice for 30 $\mathrm{min}$. The cell lysates were then centrifuged at 15,000 rpm for $15 \mathrm{~min}$ at $4^{\circ} \mathrm{C}$. The protein concentrations were measured using the Branford method. The cell lysates were separated by sodium dodecyl sulfate polyacrylamide gel electrophoresis (SDSPAGE) on $8-12 \%$ gels and electrotransferred to polyvinylidenedifluoride (PVDF) membranes (BioRad, Hercules, CA, USA). The membranes were blocked with $5 \%$ skim milk overnight at $4^{\circ} \mathrm{C}$ and then incubated for $2 \mathrm{~h}$ at room temperature with a 1:2000 dilution of the primary antibody. After washing, the membranes were incubated $30 \mathrm{~min}$ at room temperature with a 1:5000 dilution of horseradish peroxidase-conjugated secondary antibody. The proteins were then detected using a WEST-ZOL Western Blot Detection System (iNtRON, Gyeonggi, Korea).

\section{Data Analysis}

All data were expressed as the means \pm standard deviations of at least replicates. Student's t-tests and one-way analysis of variance (ANOVA) were used for statistical analyses, and differences with $P$ values of less than 0.05 were considered significant.

\section{RESULTS AND DISCUSSION}

\section{The AKR-E did not Trigger Cytotoxicity in RAW 264.7 Macrophages}

RAW 264.7 macrophages were treated with various concentrations of the AKR-E for $24 \mathrm{~h}$, and cell viability was assessed using MTT assays. Notably, when used at concentrations ranging from 50 to 200 $\mathrm{ig} / \mathrm{mL}$, the AKR-E did not induce cytotoxicity in the cells compared with that in the untreated control cells (Figure 1). However, at higher concentrations, the AKR-E was cytotoxic (data not shown). Thus, 200 $\mu \mathrm{g} / \mathrm{mLAKR}-\mathrm{E}$ was selected for further experiments.

\section{LPS-Induced Production of $\mathrm{NO}$ and $\mathrm{PGE}_{2}$ was Markedly Inhibited Decreased iNOS and COX-2 Protein Expression Following Treatment with the AKR-E}

Macrophages play a critical role in the active and passive immune responses and control a variety of inflammatory mediators, including $\mathrm{NO}$, $\mathrm{PGE}_{2}$, and cytokines. Among these mediators, $\mathrm{NO}$ plays an important role in eliminating tumors and bacterial infections. However, excessive NO formation by pathological mechanisms can result in inflammation. Moreover, excessive production of NO by overexpression of iNOSis associated with several inflammatory disorders, including septic shock and rheumatoid arthritis ${ }^{17-19}$.

The inhibitory effects of the AKR-E against LPS-induced NO production and iNOS protein expression were assessed by Griess reagent assays and western blotting in RAW 264.7 macrophages. After treatment for $24 \mathrm{~h}, 1 \mu \mathrm{g} / \mathrm{mLLPS}$ induced iNOS expression and subsequent production of $\mathrm{NO}$. Notably, treatment with AKR-E $(25,50,100$, or 200 $\mu \mathrm{g} / \mathrm{mL}$ ) reduced the level of NO production and iNOS protein expression in a concentration-dependent manner (Figures 1 and 2).

Many anti-inflammatory drugs inhibit prostaglandin synthesis through inhibition of COX-2. $\mathrm{PGE}_{2}$ is generated from arachidonic acid by $\mathrm{COX}$ enzymes, including COX-1 and COX-2. COX-1 mediates prostaglandin synthesis to regulate gastrointestinal and renal function and platelet formation. In contrast, COX-2 expression is induced by growth factors, mitogens, and cytokines and has been shown to induce inflammation-related diseases by facilitating the production of large amounts of prostaglandins. Thus, prostaglandins produced by COX-2 are thought to mediate the inflammatory response ${ }^{20-22}$. In this study, we showed that LPS significantly stimulated $\mathrm{PGE}_{2}$ production and that the AKR-E effectively inhibited the production of $P \mathrm{PE}_{2}$ in RAW 264.7 macrophages (Figure 3). Moreover, analysis of COX-2 protein expression confirmed that COX-2 was markedly downregulated (Figure 4). 


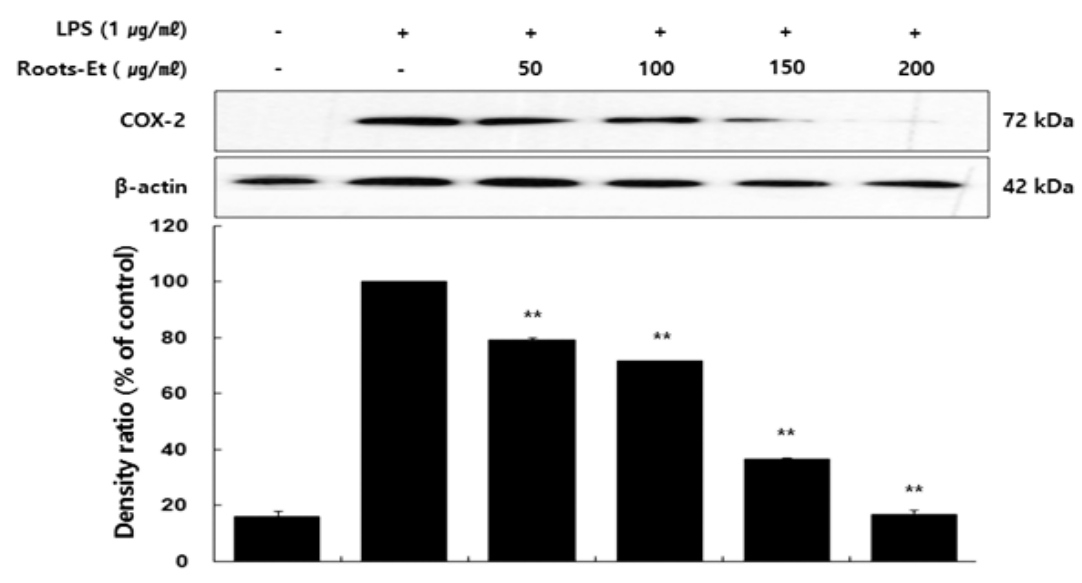

Fig. 4: Effects of AKR-E on the activation of COX $^{-2}$ in LPS-stimulated RAW 264.7 macrophages. RAW 264.7 macrophages $(5.0 \times 105$ cells $/ \mathrm{mL})$ were stimulated with LPS $(1 \mu \mathrm{g} / \mathrm{mL})$ in the hexane fraction of $A$. koreanum $(50,100,150$, or $200 \mu \mathrm{g} / \mathrm{mL})$ for $24 \mathrm{~h}$. Whole-cell lysates $(25 \mu \mathrm{g})$ were prepared, and the proteinswere separated by SDS-PAGE. The expression of COX-2 $^{-2}$ and $\beta$-actin was determined by western blotting

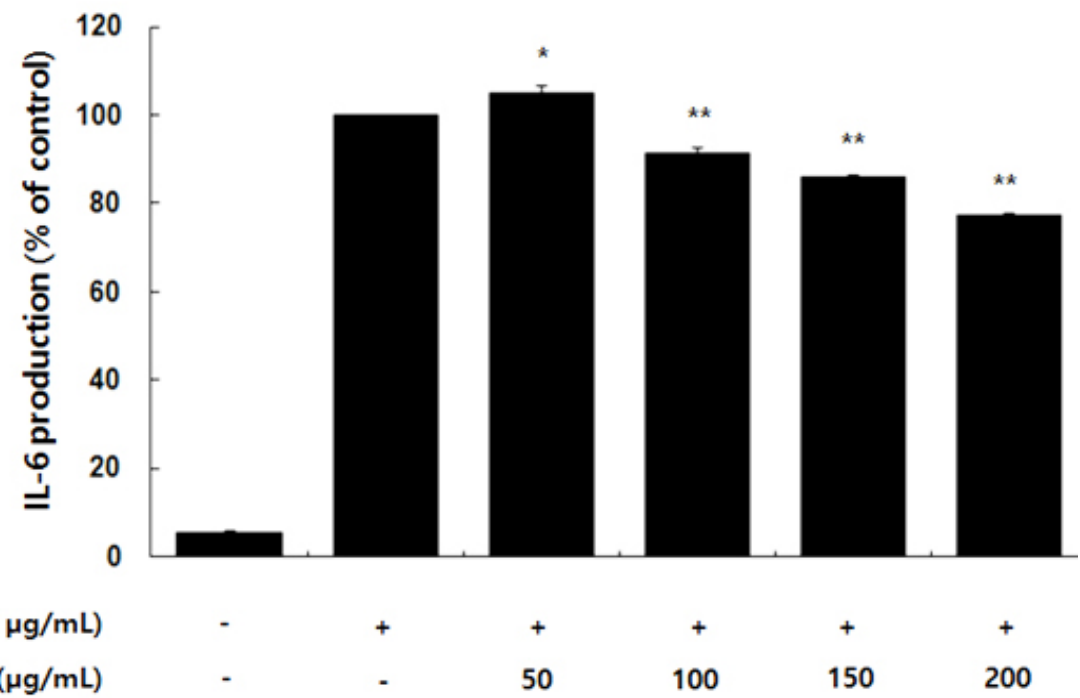

Fig. 5: Effects of the AKR-E on IL-6 production in LPS-stimulated RAW 264.7 macrophages. The cells were stimulated with $1 \mu \mathrm{g} / \mathrm{mLLPS}$ only or with LPS plus various concentrations $(50,100,150$, or $200 \mu \mathrm{g} / \mathrm{mL}$ ) of the AKR-E for 24h. IL-6 production was assayed by ELISA. The data represent the means \pm SDsof triplicate experiments. ${ }^{*}<<0.05$, ${ }^{* \star} P<0.01$ versus LPS alone.

LPS-induced Production of IL-6 and IL-1 $\beta$ was Inhibited by the AKR-E

Inflammatory mediators, such as IL-6 and $\mathrm{IL}-1 \beta$, have been regulate inflammatory responses in both in vivo and in vitro, and these cytokines are the major pro-inflammatory cytokines produced in macrophages. IL-6 is involved in the primary immune response, and $\mathrm{IL}-1 \beta$ is a key cytokine involved in the initiation and enhancement of the inflammatory response to bacterial infection. These cytokines are known to interact with each other and are generated in response to LPS stimulation ${ }^{23-25}$. In this study, we 


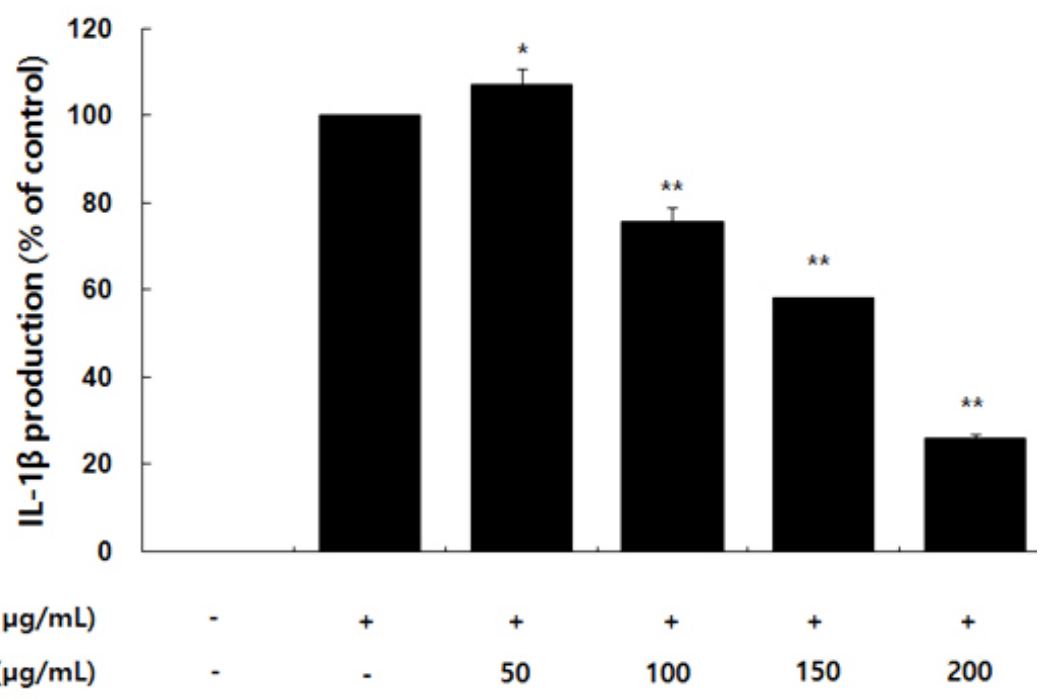

Fig. 6: Effects of the AKR-E on IL-1 $\beta$ production in LPS-stimulated RAW 264.7 macrophages. The cells were stimulated with $1 \mu \mathrm{g} / \mathrm{mLLPS}$ only or with LPS plus various concentrations $(50,100,150$, or $200 \mu \mathrm{g} / \mathrm{mL}$ ) of the AKR-E for $24 \mathrm{~h}$. IL-1ßproduction was assayed by ELISA. The data represent the means \pm SDs of triplicate experiments. ${ }^{*} P<0.05,{ }^{\star \star} P<0.01$ versus $L P S$ alone.

found that treatment with LPS induced the expression of both IL-6 and IL-1â and that subsequent treatment with the AKR-E significantly blocked these increases (Figures 5 and 6).

\section{CONCLUSION}

In summary, the AKR-E inhibited the production of $\mathrm{NO}$ and $\mathrm{PGE}_{2}$ and the expression of iNOS and COX-2 protein in RAW 264.7 macrophages. In addition, the AKR-E inhibited the production of pro-inflammatory cytokines, such as IL-6 and IL-1 $\beta$. Therefore, these results supported that the roots of $A$. koreanummay have applications as an anti-inflammatory agent, providing insights into the mechanisms of the anti-inflammatory effects of the AKR-E.

\section{ACKNOWLEDGEMENT}

This study was supported by the Innovative Fusion R\&D Program for regional industry promotion through the Korea Institute for Advancement of Technology funded by the Ministry of Trade, Industry, and Energy (R0004214).

\section{REFERENCES}

1. Yang, E.J.; Moon, J.Y.; Lee J.S.; Koh J.; Lee N.H.; Hyun C.G.; Journal of Biomedicine and Biotechnology, 2010. 2010, 715739.

2. Kang, H.S.; Kim, Y.H.; Lee, C.S.; Lee, J.J.; Choi, I.; Pyun, K.H.; Cellular Immunology . 1996, 170, 212-221.

3. Nan, J.X,; Jin, X.J.; Lian, L.H.; Cai, X.F.; Jiang, Y.Z.; Jin, H.R.; Lee, J.J.; Biological and Pharmaceutical Bulletin, 2008, 31, 738-742.
4. Nan, J.X,; Park, E.J.; Nam, J.B.; Zhao, Y.Z.; Cai, X.F.; Kim, Y.H.; Sohn, D.H.; Lee, J.J.; Journal of Ethnopharmacology, 2004,92, 71-77.

5. Jung, M.G.; Do, G.M.; Shin, J.H.; Ham.,Y.M.; Park, S.Y.; Kwon, O.; Nutrition Research and Practice, 2013, 7, 460-465.

6. Hou, D.X.; Masuzaki, S.; Hashimoto, F.; Uto, T.; Tanigawa, S.; Fujii, M.; Sakata, Y.;. Archives 
of Biochemistry and Biophysics,2007, 460, 67-74.

7. Kim, J.B.; Han, A.R.; Park, E.Y.; Kim, J.Y.; Cho, W.; Lee, J.; Seo, E.K.; Lee, K.T.; Biological and Pharmaceutical Bulletin, 2007, 30, 23452351.

8. Guha, M.; Mackman, N.; Cellular Signalling, 2001, 13, 85-94.

9. Kiyoshi, Takeda.; Shizuo, Akira.;Annual Review of Immunology, 2005,23, 307-335.

10. McDaniel, M.L.; Kwon, G.; Hill,J.R.; Marshall, C.A.; Corbett, J.A.; Proceedings of the Society for Experimental Biology and Medicine, 1996, 211, 24-32.

11. Meng, F.; Lowell, C.A.; The Journal of Experimental Medicine, 1997, 185, 16611670.

12. Willeaume, V.; Kruys, V.; Mijatovic, T.; Huez, G.; Journal of Inflammation, 1995, 46, 1-12.

13 Gerlier, D.; Thomasser, N.; Journal of Immunological Methods, 1986, 94, 57-63.

14. Liu, Y.; Progress in Neuro-Psychopharmacology and Biological Psychiatry, 1996, 23, 377395.

15. Snell, J.C.; Colton, C.A.; Chernvshev, O.N.; Gilgert, D.L.; Free Radical Biology and Medicine, 1996,20, 361-363.

16. Woo, E.R.; Lee, J.Y.; Cho, I.J.; Kim, S.G.;
Kang, K.W.; Pharmacological Research, 2005, 51, 539-546.

17. Choi, C.Y.; Park, K.R.; Lee, J.H.; Jeon, Y.J.; Liu, K.H.; Oh, S.; Kim, D.E.; Yea, S.S.; European Journal of Pharmacology, 2007, 576, 151159.

18. Aldridge, C.; Razzak, A.; Babcock, T.A.; Helton, W.S.; Espat, N.J.; The Journal of Surgical Research, 2008, 149, 296-302.

19. Shellito, J.E.; Kolls, J.K.; Summer, W.R.; American Journal of Respiratory Cell and Molecular Biology, 1995, 13, 45-53.

20. Milano, S.;Arcoleo, F.;Dieli, M.;D’Agostino, R.;D’Agostino, P.;De, Nucci, G.;Cillari, E.; Prostaglandins,1995, 49, 105-115

21. Lin, W.W.;Chen, B.C.;Hsu, Y.W.; Lee, C.M.;Shyue, S.K.; Prostaglandins and Other Lipid Mediators, 1999, 58, 87-101.

22. Eliopoulos, A.G.; Dumitru, C.D.; Wang, C.C.; Cho, J.; Tsichlis, P.N.; The EMBO Journal, 2002, 21, 4831-4840.

23. Beuscher, H.U.; Gnther, C.; Rllinghoff, M.; Journal of Immunology, 1990, 144, 21792183.

24. Jang, C.H.; Choi, J.H.; Byun, M.S.; Jue, D.M.; Rheumatology (Oxford),2006, 45, 703-710.

25. Wan, Y.; Freeswick, P.D.; Khemlani, L.S.; Kispert, P.H.; Wang, S.C.; Su, G.L.; Billiar, T.R.; Infection and Immunity, 1995, 63, 24352442. 